\title{
Quantifying Mobility: A Proposed Index Model
}

\author{
Radwan Ali, Humayun Zafar \\ Kennesaw State University
}

\begin{abstract}
Mobile technologies are usually viewed from a consumer perspective. For this reason, companies continue to look into enhancing the mobile user's experience through evolved apps that are embedded in their daily lives. Since mobility is much more than apps, we contend that countries and cities will need to make themselves amenable to companies that invest in this area. However, there is no standard method of quantifying where a city ranks when it comes to it being attractive for a company. For this reason, we are proposing a mobility index.
\end{abstract}

\section{Introduction}

The concept of an economic index appeared in the 1920 s and gained popularity since the 1960 s as it provides an artifact that one can use to compare outcomes. For example, the CPI assesses the variation in price for a consumer's market basket of goods or services. The Bureau of Labor Statistics (BLS) came up with the CPI to illustrate inflation trends. The CPI looks at buying groceries, buying a house or land, or purchasing some services such as lodging or car maintenance. The number and types of economic indices increased in numbers and included quantitative (hard) and qualitative (soft) [60].

The main reason behind the development of economic indices is the need for countries or cities strive for a competitive advantage (EIU, 2012). An index usually represents the wellbeing of a country (or a city) based on some aggregate output of factors. The better the ranking, the more appealing an entity becomes with respect to attracting human talent, business investments, and consequently, better ranking. For example, it is undeniable that New York is considered one of the most attractive destinations in the world as it offers professional and personal opportunities that satisfy a multitude of needs.

Technological advances are the main source of economic growth [55], [15]. One huge motivation is the profit aspect of any new ideas or products. Mobile technologies exemplify this pursuit. Businesses of varying sizes across all industries have aggressively mobilized their apps and content. Also, with the advent of Internet of Things (IoT) mobility transforms into an entirely different dynamic of being embedded everywhere. With such shifts, it is imperative that countries and cities realize that future growth will be dependent on their attractiveness toward mobile technologies.

The purpose of this research is to introduce a Mobility Index. During our research, we explored the effect of mobile technologies on economic and social conditions. Many constructs appeared in the literature. Some of these constructs include competitiveness, diffusion of technology, human capital, in addition to others. We expand on these in the next section.

\section{Literature Review}

The nature of this research lends itself to many different disciplines such as economics, social sciences, and technology innovation. Accordingly, this section spans many inter- and intra-disciplinary sources.

The use of indices has been increasing as assessment tools to relay the ranks of entities such as cities, countries, and organizations in terms of performance [43]. Sometimes, indices are used to measure economic (e.g. inflation) and social (e.g. obesity) phenomena by using factors and their weights with respect to time series [7]. Regardless of the phenomenon to measure, the main objective of an index is to provide reliable output that can help decision-makers with understand the economic situation [60], and consequently, prepare for the new conditions.

Composite indices (CIs) are mathematical models (equations) that are chosen (or generated) based on certain need. To be useful, these models have to fit an intended purpose and generally-accepted principles [10], [43]. Yet, their articulations vary according to the crafters of these models. Additionally, identifying the specifications of the various factors, deciding what factor to include, and what order to assign to these factors, specifically, in terms of weights. There are three aspects associated with conceptualization a new index: 1) identifying dimensions (factors or indicators), 2) determining their ranks (weights), and 3) using a fitting model (equation) [43]. These aspects are major challenges because of the wide-array of approaches and perspectives [58]. Each of these aspects has its own set of tasks. 
Identifying dimensions of an index system can be a daunting task especially when there is opportunity for subjectivity, meaning human sample involvement. The main step of this process is determining what is being measured. The idea is to specify the intended outcome and plan backward toward its forming factors. Before getting to the factors, some design measure should be put in place. Wang and $\mathrm{Xu}$ (2007) stressed that an index system should have scientific, systemic, feasible and comparable in principles for guidance. Zhang et al. [58] provided more three specific principles: 1) item analysis, 2) factor analysis, and 3) validity analysis. For the item analysis, setting a threshold (they called critical ratio $(\mathrm{CR})$ ) is recommended so that some items that do not me the $\mathrm{CR}$ value can be eliminated. As for the factor analysis, they suggested construct validity $(\mathrm{CV})$ to help augment the final index. For the third principle, they emphasized on assessing the reliability of the index system and added a specific model with their rationale:

$$
R=\frac{K}{K-1}\left(1-\frac{\sum \delta_{i}^{2}}{\delta^{2}}\right)
$$

Where $\mathrm{K}$ is the number of the evaluation index, $\delta$ is the measured total score variance, and $\delta_{\mathrm{i}}$ is the measured total score of each indicator. They considered 0.7 the minimum limit for an index system with high reliability. After the seemingly exhaustive factor selection process, another challenging task of assigning weights to these factors becomes the next step. The rationale behind the weights is trying to minimize subjectivity by having the best possible scale for calculation. There is always that human tendency for bias and use of measurements that pay off in competitive advantage (Kao and Hung, 2005). Chowdhury and Squire [11] acknowledge the concerns that are associated weights. They argued that equal weights can be effective as a compromise. They based that argument on their work surveying researchers from 60 countries. Because developing an index is multiphased process, subjective input can play a role in any phase [10]. Hence, efforts should be made to account for the possibility in addition to placing some protection measures. These weights are essential to articulating the model equation.

Using the proper model is another hard and important step. Macroeconomic indexing provides a means of distilling meaning from seemingly erratic aspects of human nature. It is defined as a piece of economic data, usually of macroeconomic scale, that is used by investors to interpret current or future investment possibilities and judge the overall health of an economy. The complexities of the modern macroeconomic environment are so diverse that analysis of the affecting factors requires abstraction of single sector of the economy by reducing the number of variables to measurable proportions and finding a way to measure them (Fine, 1981). In our case, we have begun developing a mobility index that will provide a ranking system of the competitive environment of major cities in regard to their mobile and wireless readiness and infrastructure growth.

\section{Theoretical Framework}

Innovation undeniably plays an important role in society as it affects economy and culture. The entrepreneurial nature of innovation produces huge influence on the marketplace. It is considered one of the critical factors in economic change [9]. The theory of economic innovation was attributed to Joseph Schumpeter [51]. He was an Austrian economist whose views about the role of innovation surfaced in the early 1910s. The current state of technology is a luminous indicator of human innovation and a concerted illustration of the core of Schumpeter's theory. We find that entrepreneurial aspect of Schumpeter's theory [12] to be a fitting framework for our current project as mobile-based technological advancements continue to propel changes in culture, and consequently, in economic conditions.

Schumpeter's work [47] thought that innovation was an economic change agent because it often resulted in monopolies that pushed competition to develop new products. Heertje [25] explained that Schumpeter envisioned innovations came in "swarms" because one innovation activity triggers others and thus forming combinations of other new activities. Allen [2] concurred that new products and processes are bound to cause activity in the economy. The focus must be that Schumpeter's emphasis was that entrepreneurial behavior was and will be always a factor in all aspects of economic development. Schumpeter's thoughts on innovation were in relevance to entrepreneurship and social change [12]. We can simplify the theory of economic innovation into two statements: 1) innovation is an indicator of entrepreneurship, and 2) innovation breeds more innovation. Entrepreneurs have great influence on economy as they bring new ideas, new business models, and [55]. The message from Schumpeter is that innovation and competition generate positive change in quality of life [15]. As a present-day example, one can easily attest to the salient innovations in the cellular phone (especially the iPhone and mobile devices).

Many modern-day economists still see Schumpeter's work as prophetical as it still resonates with our current conditions [12]. In concurrence, Dopfer [16] stressed the same aspect of Schumpeter's work and how it applied to the present day because it provides a good framework for resolving our complex problems in our technology- 
dependent economy. McCraw [35] highlighted that as one of Schumpeter's long-lasting contributions was combining economics with society and history. That allowed for extensive attention to economic and social development. Festre and Garrouste [18] acknowledged that as interesting perspective and showed its influence on institutional change. Endres and Woods [17] added that Schumpeter's theory provided a conduct model that is affected by extrinsic and intrinsic elements.

It is noteworthy that Schumpeter has had his share of detractors. While some economists appreciated Schumpeter's enthusiasm to the influence of innovation but differed with him on the source of that movement. Scherer [45] thought that innovation might not have to do with an organization's ability to do research and development to advance new ideas or products. Gilbert [22] agreed that Schumpeter's suggestions that large organization have better potential for innovation. He added that that effect of competition on innovation was not as a clear indicator as Schumpeter had believed.

\section{Methodology}

Establishing a measuring index is a complex process as it spans many human and data factors. Battaglia and Fenga [7] insisted that a large set of factors should be considered using historical archives and human input to produce a list of these factors and their values. Nardo et al. [37] added that such process must be careful and that it should acknowledge bias and allow for compromise.

We focused on mining the literature for previous index studies to carve our index. We relied on published works and found relevant expertise that helped us choose the following factors as components of our index: Gross domestic product (GDP), institutional environment, cost of doing business, labor, technology infrastructure, quality of service, and mobile transactions and activities. The next section will explain these and provide the rational for using them in the Mobility Index model.

\section{Findings}

We have established that the purpose of the index was to assess a city's rank as a hub for mobile technology investment. Based on the study of the index-relevant literature, our research has identified seven measurable city-related factors that must be included in the articulation of an index of mobile technology. The seven factors are explained in the following paragraphs.

\subsection{Gross Domestic Product Per Capita (GDPPC)}

Bohlin et al. [8] investigated the factors that influence the diffusion of mobile technologies across determinants of mobile diffusion of successive generations of mobile telecommunications technologies across a 62 developed and developing countries. They found that many factors that influenced location parameters such as urbanization, GDP per capita and Internet or broadband penetration. In addition, they also found that regulation played a significant role in adoption of these technologies. Similarly, Dewan, Ganley, and Kraemer [13] conducted a multi-country study exploring the influence of information technology (IT) penetration on the economic standing of a country. They found that there was a positive correlation between IT adoption and the national income. They added that the wider the IT adoption was, the stronger the economic conditions. Pick and Azari [40] concurred, they shared that diffusion of technology affects productivity positively and hence living standards. So, there is that strong connection between technology adoption and national or personal per capita. Mariano and Murasawa [34] made a case for using a GDP in their index research. They claimed that using the GDP was important to get a good indication of the business cycle in a country. GDP can be combined with other factors to provide information about the economic state of a county or a city. Timmer and van Ark [52] compared the effect of the adoption of information technology on productivity in the U. S. and compared it with countries in the European Union (EU). They used the GDP in the countries to gauge the economic wellbeing of each. They found that there was a positive correlation between IT and GDP. Based on the findings of these studies, we posit that any index model that is economic related can benefit from the use of GDP as an important factor. This document will use $\boldsymbol{G}$ to denote the GDP factor.

\subsection{Institutional Environment}

While GDP is usually government-produced and monitored, the government is hugely interested in the improvements of socioeconomic conditions. In a study about the influence of information technology on countries, Azari and Pick [5] found out that countries with solid governmental and legal infrastructure had better socioeconomic condition than those with weak involvement. The researchers concluded that governmental help of business via favorable initiatives. These can encourage business to invest in technology and other venture, an in turn, can help governmental societal priorities. Fan and Watanabe (2006) shared that sentiment in their study of Japan and China's technology policies. They 
suggested that governments can do many things on behalf of business including locating helpful technology, charting helpful laws, and even negotiating agreements and licenses with companies in other countries. Lopez-Claros and Mata [32] used the innovation capacity index (ICI) to explain how countries differed in their socioeconomic conditions. The index included five-pillars: 1) institutional environment, 2) human capital, education, and social inclusion, 3) regulatory and legal framework, 4) research and development, and 5) adoption and use of information and communication technologies. With this index, the first four have some governmental underpinnings. Khakbaz [27] used the framework provided by Lopez-Claros and Mata [32] to examine factors that influence regional innovations. He used a focus group of experts to examine the effectiveness of framework. The paper argued that government can and should play an active role in building infrastructure and adopt regulation that are helpful to business, and hence, benefit its citizens. On a small scale, Anderson [3] examined state tax rankings around the U. S. as indicators for a state's economy. His study intended to facilitate policy-making by minimizing confusion over the meaning of the tax ranking and the size of a state's government. He explained that these rankings provided clarification about factor markets, human capital, entrepreneurship characteristics, and other features of state economies. Based on these studies, we posit to use governmental regulations and involvement as institutional environment, and to denote that with $\boldsymbol{E}$.

\subsection{Cost of Doing Business}

Business organizations seeking to re-locate or expand to new locations, costs and benefits are weighed to justify the potential move. We established in the previous section that a city's business-friendly institutional environment is essential to attracting business ventures. In addition, other factors, such as the cost of running a business, are considered. Anderson [3] lists and discusses many existing indices that look at the cost of business to illustrate the importance of this factor in decision-making. He points out taxes as one of the first factors to consider for business to re-locate or expand. Similarly, Kolko, Neumark, and Mejia (2013) include many other indices but cite the Cost of Doing Business Index by the Milken Institute as an important reference for decision-making. The explained that the information given by the index "...capture something meaningful about state business climates, insofar as the outcome of interest is economic growth...". Piotti [41] shares that cost is an important factor for a business' decision to relocate. The cost can be represented in real estate prices, labor, and taxes in addition to other expenditures. Han and Mithas [23] concur that reducing cost, especially in IT, influences decisions immensely. They discuss cost in terms of IT outsourcing, nonetheless, it is relevant for this article with respect to economic conditions at a potential future site of some business. That cost of doing business is one of many things that Policy makers must understand and treat with care when it comes to economic indices [3]. Based on this information, we post the cost of doing business should be included in an economic index such as ours here, the Mobility Index. We will denote this factor with $\boldsymbol{C}$.

\subsection{Labor}

The cost of doing business spans many aspects including labor and labor availability plays is key innovation spread, and consequently, productivity [27]. The availability of labor is affected by the number of skilled workers in some business market, the presence of formal degree education programs or vocational training programs, in addition to wage matters. Caselli and Coleman (2013) recognized the importance of skilled labor by comparing the productivity levels among countries. They found that there was a skill disparity in cross-country technology differences and that countries with better wages use labor more efficiently. They explained that in countries where there was abundance of skilled-labor technology is used at higher level and more efficiently. Khakbaz [27] cited many sources in his study and listed labor as human capital, as one of the reinforcing factors that influence innovation capacity and area growth. He reiterated the association between technology and labor skills. Lopez-Claros and Mata [32] agreed that labor encourage investments in innovation. They also listed per capita income, education levels, variety of tastes, and infrastructure.

Hava and Azer [24] also explored the relationship between IT investments and labor. They reciprocated between technological innovations and labor productivity. They found that the bigger the investment in technology, the higher the labor productivity. And they added that the more productive the labor force, the better the situation for investments. In a similar study, Smith and Waters [49] looked at the role of labor in regional innovation. They concluded that labor was critical to regional economic activities and that skilled labor was attracted to areas with economic opportunities. They suggested that local government should nurture skilled labor through programs. Lopez-Claros and Mata [32] agreed that labor encourage investments in innovation. We will include labor as another forming factor of our intended index, it will be denoted with L. 


\subsection{Technology Infrastructure}

Considering the premise of this document, mobile technology is the main construct. We are in the process of establishing an index that gauges the ranking of a city for mobile technology readiness. Roberts and Grover [42] defined infrastructure as "... an arrangement of shared technical components and IT services: platforms, networks and telecommunications, data, and software applications...". They conducted a research on the influence of IT infrastructure on high-tech firms' abilities to sense and respond to customer's needs. Their findings emphasized the importance of using IT to a firm's competitive advantage, and consequently, success. Kumar [28] also emphasized the roles of IT infrastructure and provided some features that make effective. He listed criteria such as reliability with respect to performance, flexibility with respect to adaptability to changing conditions, and upgradability with respect to being scalable and able to integrate advanced technologies. The model will use $\boldsymbol{I}$ to represent the technology infrastructure factor.

\subsection{Quality of Service}

A good measure of the value of any technology infrastructure is the value it provides to the end-user, the customer. One way to assess that value is to investigate the quality of service that depends on said structure. Roberts and Grover [42] used the term customer agility to denote the speed and efficiency by which a firm can respond to a customer's need. They explained that the quality of service of a system is important to the providing firm as well as the customer. For the providing firm, it can benefit from recognizing potential customer opportunities, and thus responding accordingly. Hence, we posit that quality of service is another important factor that touches the mobility readiness of a city. It will be included in our model and will be represented by $\boldsymbol{Q}$.

\subsection{Mobile Transactions}

Previously, we discussed the importance of the IT infrastructure and the quality of service that might result. We made a case about their importance to the success of any IT-based business venture. Bohlin et. al. [8] listed per capita income, urbanization, broadband penetration, and regulation as deciding factors for a region's economic status. They looked at penetration to be the most indicative measure of technology diffusion. They defined penetration as the number of people with respective Internet access per 100 inhabitants. We believe that the figures associated with mobile technology-related activities provide good indicators about the level of acceptance and adoption. These activities may include trade and retail transactions, mobile app sales and usage, and are important to investigate. One example is the use of mobile devices to make payments [26]. She discussed the new business model that mobile technology has brought for business transaction included mobile payments. Accordingly, firms should adapt to new models by implementing new approach to business process. Au and Kauffamn [4] acknowledged the importance of mobile transactions to the emerging economy. They mentioned the new business model and offered advice for business firms to accommodate it. Such model has been gaining popularity because of its appeal to the consumer. As well, Yang [57] emphasized the role of mobile transaction and consumer behavior. He equated mobile consumer activities to a determinant for prosperity, and hence, should be investigated and analyzed. In relevance, Kent [26] listed many stakeholders that are affected by mobile transactions including mobile payment application developers and mobile device manufacturers in addition to others. She also included the importance of cooperation among them to advance the mobile technology segment. Accordingly, we posit that mobile transactions should be considered when assessing the mobility readiness of a city. Hence, we will use $\boldsymbol{M}$ to denote mobility transactions in our model.

\section{The Model}

Our index will essentially pull its rankings from a modified neoclassical growth model and will factor in some more general economic variables such as city population, per capita GDP, tax rates on business as well as consumers, and cumulative capital investment, infrastructure variables such as electricity production, available network speeds, the number of mobile-based organizations, and the number of mobile transactions that occur, workforce readiness in terms of quality of educations as well as the number of information workers present in the city. These factors will be collected and assigned a weighted average which will then be calculated and sorted to provide our ranking index. Without in depth analysis of these factors and others a ranking system would serve as simply pure conjecture.

For the time being, we are going to focus on the neoclassical growth model for purposes of proving our abilities in creating an index. The neoclassical growth model attempts to explain long run economic growth by looking at productivity, capital accumulation, population growth, and technological progress. The neoclassical growth model has served as the starting point for many macroeconomic analyses such as human capital development, international trade, and technological spillover. Such use of the model has been used as a basis in Izushi 
and Huggins "Empirical analysis of human capital development and economic growth in European regions" which holds the implications that a high level of investment by individuals in tertiary education is found in those regions that accommodate high-tech industries and holds that those regions supported by urban infrastructure enjoy a low unemployment rate. Bernhofen (2008) also uses the neoclassical model in his paper, "Predicting the Pattern of International Trade in the Neoclassical Model: A Synthesis" to serve as a predictor model for international trade in which he proposes that the, "notion of predictability serves as an organizing principle for characterizing pattern of trade predictions in [a] single economy and integrated equilibrium formulations of the neoclassical trade model". Trefler (1995) discussed the model and also assumes there are technology differences across countries which are common across sectors and that a technological improvement increases the effective supply of all factors proportionately.

Since this index is being designed to focus on determining the economic competitiveness of major cities in regard to their mobile-readiness, long run growth must be looked at with a focus technological progress and infrastructure, productivity, quality of human capital, as well as population growth- all of which is encapsulated in the neoclassical growth model (Rima, 2006). Technological factors are not the only indicator of growth as is examined in Adriana Di Liberto's, “Convergenza E Divergenza nei Modelli Di Crescita Neoclassici con Capitale Umano," in which she provides the necessary link between the theory on growth, convergence and human capital and the empirics of convergence. Due to the models proven focus on technological progress, its stress on human capital development, as well as its continued use in the macroeconomic tradition when analyzing macroeconomic environments we will conclude that it will be an acceptable starting position to being making inferences in regards to the macroeconomic standing of the cities we wish to analyze.

The model was further chosen due to its basis on the theory that macroeconomic development is based not only on population growth, but is also weighted based on technological progress, which will take in the law of diminishing returns. The law of diminishing returns is all too familiar in the technological sector, where you might find that increasing the number of devices per employee may not improve productivity in the least, but increasing the efficiency of the devices should increase the employee's productivity marginally.

For the beginning of this analysis we need to start with a production function. In this case we will have two technology-related variables: Labor augmenting (Z) and the non-labor augmenting or neutraltechnology (A). These variables, in regard to technology, will serve to measure the efficiency of technology as well as the amount of technological progress being made. The equation is as follows:

$$
Y_{t}=A_{t} f\left(K_{t}, Z_{t} N_{t}\right)
$$

This is a basic production function for our simplified model of our complex economy that makes certain assumptions about behavior and ownership, such as time $(\mathrm{t})$ has a range $[0, \mathrm{t}]$, and that firms use capital and labor to produce output. The variables as yet undefined in this equation are as follows: $\mathrm{Y}$ as output, $\mathrm{K}$ as capital, and $\mathrm{N}$ as current population. Capital in this model may also refer to human capital, which would refer to things such as quality of education or investment in the skills of the labor force. In this model output can either be consumed (C) or reinvested back into the company in the form of new capital goods (I). Due to this our aggregate, accounting identity will be as follows:

$$
Y_{t}=C_{t}+I_{t}
$$

Accumulation of capital will assume a period of delay between when it is acquired and when it becomes productive and it will assume a rate of depreciation of $0<\delta<1$. Its equation is as follows:

$$
K_{t+1}=I_{t}+(1-\delta) K_{t}
$$

These three equations can then be combined and simplified to produce the following equation:

$$
K_{t+1}=A_{t} F\left(K_{t}, Z_{t} N_{t}\right)-C_{t}+(1-\delta) K_{t}
$$

The equation provide us with two variables of flux population growth $(\mathrm{N})$ and technological progress (Z). In order to stabilize these variables, we divide by $\mathrm{ZN}$, which will produce:

$$
\frac{K_{t+1}}{Z_{t} N_{t}}=\frac{A_{t} F\left(K_{t}, Z_{t} N_{t}\right)}{Z_{t} N_{t}}-\frac{C_{t}}{Z_{t} N_{t}}+(1-\delta) \frac{K_{t}}{Z_{t} N_{t}}
$$

By defining the following variables, we can rewrite the constraint:

$$
\begin{gathered}
c_{t} \equiv \frac{C_{t}}{Z_{t} N_{t}}, y_{t} \equiv \frac{Y_{t}}{Z_{t} N_{t}}, k_{t} \equiv \frac{K_{t}}{Z_{t} N_{t}} \\
\frac{K_{t+1}}{Z_{t} N_{t}}=A_{t} f\left(k_{t}\right)-c_{t}+(1-\delta) k_{t}
\end{gathered}
$$

In order to put our equation in terms of our non-labor augmenting technological variable, we must divide by:

$$
Z_{t+1} N_{t+1}
$$


s.t.

$$
\frac{K_{t+1}}{Z_{t+1} N_{t+1}} \frac{Z_{t+1} N_{t+1}}{Z_{t} N_{t}}=A_{t} f\left(k_{t}\right)-c_{t}+(1-\delta) k_{t}
$$

And with the assumptions:

$$
Z_{t+1}=(1+z) Z_{t}, N_{t+1}=(1+n) N_{t}
$$

We can then simplify further to:

$$
\gamma=(1+z)(1+n)
$$

The growth metric formula provides a simple and eloquent way of showing economic output through technological progress as well static population. This model will provide a starting point for further analysis of the macroeconomic environments in which we wish to index. It will allow us to generate a metric based off our labor force growth rate (n) and our technological progress (z). Since multiple facets of each of our independent variables must be considered they must first be categorized between our two independent variables (labor force growth rate and technological progress) and since our independent variables are calculated based off of growth rate percentages we can assign a weight (w) based on significance to the model and then perform a weighted average of our percent growth numbers within each category. This can be done with confidence since our growth rate percentages carry no measurement values such as dollars spent or bytes transferred and can therefore be compared with impunity. Our resulting weighted average will then be plugged into our equation to form our metric as follows:

$$
\begin{aligned}
& \mathrm{Z}=\frac{\sum_{k=1}^{i} w_{1} z_{1}+w_{2} z_{2}+\cdots+w_{i} z_{i}}{i} \\
& n=\frac{\sum_{k=1}^{i} w_{1} n_{1}+w_{2} n_{2}+\cdots+w_{i} n_{i}}{i}
\end{aligned}
$$

With the assumption that:

$$
w 1+w 2+\cdots+w_{i}=1
$$

will then provide us with the finalized model:

$$
\begin{aligned}
& \gamma \\
& =\left[1+\left(\frac{\sum_{k=1}^{i} w_{1} z_{1}+w_{2} z_{2}+\cdots+w_{i} z_{i}}{i}\right)\right][1 \\
& \left.+\left(\frac{\sum_{k=1}^{i} w_{1} n_{1}+w_{2} n_{2}+\cdots+w_{i} n_{i}}{i}\right)\right]
\end{aligned}
$$

For the time being, labor force growth rate will be measured using population data and city specific unemployment rates, and technological progress will be measured by the total budget allocation of the Department of Information Systems for our respective cities. As a result of the discussion for the findings, we shared in this section the following linear model:

$$
\begin{gathered}
I=w_{1} * \mathrm{G}+w_{2} * \mathrm{E}+w^{*}{ }^{*} \mathrm{C}+w_{4} * \mathrm{~L}+ \\
w_{5} * \mathrm{~T}+w_{6} * \mathrm{Q}+w_{7} * \mathrm{M}
\end{gathered}
$$

Factors such as GDP, electrical production, network speeds, cumulative capital investment, number of information workers and those workers with technological experience / education, cost of information labor, revenue from Mobile device sales, as well as proximity to a major airport that airport's IT facilities as well as it flight frequency will be incorporated in the future in the same manner.

\section{Significance and Implications}

Many indices are used to assess different economic measures such as productivity, consumption, financial investments, and similar constructs [43]. Because technological innovations have become fixtures in today's economy, it is important that they are monitored and that their impact is gauged. As technology evolves, new trends appear. McKinsey Global Institute [36] conducted a study and identified twelve technologies that would have the have the greatest impact on the global economy. At the top of the list was the mobile Internet. At the start of the 2015, mobile technology accounted for $3.2 \%$ of the U. S. GDP ( $\$ 548$ billion), and it will increase to $5 \%$ in 2020 (Boston Consulting Group, 2015). Because of mobile technology's disruptive (life-changing) nature, its trends have taken on a great force in the global economy. The widespread of mobile technologies has encouraged more innovations, increased productivity for many countries, and tempted many investments at local and national levels [30]. Such a force calls for harnessing that can be facilitated by performance measures. The model generated here provides such measures.

\subsection{Discipline Implications}

As established earlier, there are many indices that assess economic impact of technology. The discipline of information systems has provided a good amount of research on Internet mobile technologies [4], [33]. and presented many models for diffusion. However, particular economic models that look at mobile technologies are still lagging. There are many studies on mobile learning and others are on mobile marketing [24], [6]. 


\subsection{Managerial Implications}

This project was initiated by the need for a city to assess its rank at a mobile technology-oriented business destination. The authors believe that the linear model suggested here can provide such assessment. A city can use this model to tempt business firms by showcasing its amiability. Firms, in turn, and rely on the model for a decision-making tool. This can provide a competitive advantage as it is known that competing among business organizations positively influences advances in technological products [8]. Additionally, this type of economic model can provide a motivation to explore and study matters in relevance to technological advances, new regulations, embracing, more efficient business processes, and hence, more robust strategies [30], [4]. Furthermore, competition can expand innovations and commercialization and increasing share in the marketplace [21]. Such perspective encourages adoption of models like the one presented in this study.

\section{Conclusion}

The purpose of this research work is to generate a thoughtful and useful an assessment indicator that can help business organization in decision-making with respect to investment in mobile technology initiative. The authors used academic and businessoriented literature to generate seven measureable factors (or sub-indicators) to form a linear model based. Additionally, the authors believe that the linear model generated here was derived from a rich index-relevant literature that focused on economic productivity and performance. They believe that such a model can help assess innovations in mobile technologies, and furthermore, it can be used as a foundation for future models that can predict such innovations. This piece needs to be vigorously explored.

\section{References}

[1] Acemoglu, D., (2010). When Does Labor Scarcity Encourage Innovation? Journal of Political Economy, 118 (6), 1037-1078.

[2] Allen, R. L., (1991). Opening Doors: The Life and Work of Joseph Schumpeter. New Brunswick, NJ: Transaction Publishers.

[3] Anderson, J. E., (2012). State Tax Rankings: What do they and don't they tell us? National Tax Journal, 65 (4), 985-1010.

[4] Au, Y. A., and Kauffman, R. J., (2008). The economics of mobile payments: Understanding stakeholder issues for an emerging financial technology application. Electronic Commerce Research and Applications, 7, 141-164.

[5] Azari, R., and Pick, J. B., (2009). Understanding Global Digital Inequality: The Impact of Government, Investment in Business and Technology, and Socioeconomic Factors on Technology Utilization. Proceedings of the 42nd Hawaii International Conference on System Sciences.

[6] Bauer, H. H. Reichardt, T., Barnes, S. J., Neumann, M. M., (2005). Driving consumer acceptance of mobile marketing: A theoretical framework and empirical study. Journal of Electronic Commerce Research, 6 (3), 181-192.

[7] Battaglia, F., and Fenga, L., (2003). Forecasting composite indicators with anticipated information: an application to the industrial production index. Applied Statistics, 52 (3), pp. 279-290

[8] Bohlin, A., Gruber, H., and Koutroumpis, P. (2010). Diffusion of new technology generations in mobile communications, Information Economics and Policy, 22 (1), 51-60.

[9] Carroll, P., (2006). An introduction to economics with emphasis on innovation.

[10] Cherchye L., Moesen, W., Rogge, N., Van Puyenbroeck, T., Saisana, M., Saltelli, A., Liska, R., Tarantola, S., (2008). Creating composite indicators with DEA and robustness analysis: the case of the technology achievement index. Journal of the Operational Research Society 59:239-251.

[11] Chowdhury, S., and Squire, L., (2006) Setting weights for aggregate indices: an application to the commitment to development index and human development index, Journal of Development Studies, 42, 761-71.

[12] Croitoru, A., (2012). A review to a book that is 100 years old. Journal of Comparative Research in Anthropology and Sociology, 3(2), 137-148.

[13] Dewan, S., and Riggins, F. J., (2005). The Digital Divide: Current and Future Research Directions." Journal of the Association for Information Systems, 6 (12), pp-pp.

[14] Despotis, D.K., (2005) A reassessment of the Human Development Index via data envelopment analysis, Journal of the Operational Research Society, 56, 969-80. 
[15] Diamond, A. M., (2006). Schumpeter's creative destruction: a review of the evidence. Journal of Private Enterprise, 22(1).

[16] Dopfer, K. (2012). The Origins of Meso Economics: Schumpeter's Legacy and Beyond. Journal of Evolutionary Economics, 22(1), 133-60.

[17] Endres, A. M., Woods, C. R., (2010). Schumpeter's 'conduct model of the dynamic entrepreneur': scope and distinctiveness. Journal of Evolutionary Economics, 20(4), 583-607.

[18] Festre, A. and Garrouste, P., (2008) Rationality, behavior, institutional, and economic change in Schumpeter. Journal of Economic Methodology, 15(4), 365-390

[19] Fink, L., and Neumann, S., (2007). Gaining agility through IT personnel capabilities: The mediating role of IT infrastructure capabilities. Journal of the Association for Information Systems, $8(8), 440-462$.

[20] Foster, J. E., McGillivray, M., Seth, S., (2013): Composite Indices: Rank Robustness, Statistical Association, and Redundancy, Econometric Reviews, 32(1), 35-56

[21] Furman, J. L., Porter, M. E., Stern, S. (2002). The determinants of national innovative capacity. Research Policy, 31, 899-933.

[22] Gilbert, R. J., (2006). Looking for Mr. Schumpeter: Where Are We in the CompetitionInnovation Debate? Innovation Policy and the Economy, Vol. 6, 159-215.

[23] Han, K., and Mithas, S., (2013). Information technology outsourcing and non-IT operating costs: An empirical investigation. MIS Quarterly, 37 (1), 315-332.

[24] Hava, H. T., and Azer, O. A., (2011). The Effect of Information Technological Investments on Labor Productivity with the View of New Economical Connections. European Journal of Economics, Finance and Administrative Sciences, 33, 56-62.

[25] Heertje, A., (2006). Schumpeter on the Economics of Innovation and the Development of Capitalism. Edward Elgar Publishing

[26] Kent, J., (2012). Dominant mobile payment approaches and leading mobile payment solution providers: A review. Journal of Payments Strategy and Systems, 6(4), 315-324.
[27] Khakbaz, P. P., (2012). Regional Innovation Capacity in Development Regions and Cities: A Sustainable Approach. Journal of Economics and Behavioral Studies, 4(4), pp. 223-226.

[28] Kumar, R. L., (2004). A Framework for Assessing the Business Value of Information Technology Infrastructures. Journal of Management information Systems, 21(2), 11-32.

[29] Kuo, E., (1990). Information technology and Singapore society: trends, policies, and applications: symposium proceedings. Kent Ridge: Singapore University Press, 29-37.

[30] Lee, S., Marcu, M., Lee, S., (2011). An empirical analysis of fixed and mobile broadband diffusion. Information Economics and Policy, 23, $227-233$

[31] Linstone, H. A., and Turoff, M., (1975). The Delphi method: Techniques and applications. Boston, MA: Addison-Wesley.

[32] Lopez-Claros, A., and Mata, Y. M., (2010). The Innovation Capacity Index: Factors, policies, and institutions driving country innovations. In The Innovation for Development Report.

[33] Lu, J., Yao, J. E., and Yu, C., (2005). Personal innovativeness, social influences and adoption of wireless Internet services via mobile technology. The Journal of Strategic Information Systems, 14(3), 245-268.

[34] Mariano, R. S., and Murasawa, Y., (2002). A New Coincident Index of Business Cycles Based on Monthly and Quarterly Series. PIER Working Paper No. 02-014. http://ssrn.com/abstract=317983 (Access Date: May 11, 2018).

[35] McCraw, T. K., (2007). Prophet of Innovation: Joseph Schumpeter and Creative Destruction. Cambridge, Mass., Harvard University Press.

[36] McKinsey Global Institute (2013). Disruptive technologies: Advances that will transform life, business, and the global economy.

[37] Nardo, M., Saisana, M., Saltelli, A., Tarantola, S., Hoffman, A., and Giovannini, E. (2005). Handbook on constructing composite indicators: methodology and user guide, OECD Statistics. Working Paper STD/DOC, OECD, Paris.

[38] Patterson, K. D., (2002). Modeling the Data Measurement Process for the Index of Production. Journal of the Royal Statistical Society, Vol. 165, No. 2, pp. 279-296 
[39] Permanyer, I., (2011). Uncertainty and robustness in composite indices rankings. Oxford Economic Papers 64 (2012), 57-79.

[40] Pick, J. B., and Azari, R., (2008). Global Digital Divide: Influence of Socioeconomic, Governmental, and Accessibility Factors on Information Technology. Information Technology for Development 14(2), 91-115.

[41] Piotti, G., (2009). Cost Reduction through Relocation, or the Construction of Myths in Discourse. Competition and Change, 13 (3), 305326.

[42] Roberts, N. and Grover, V., (2012). Leveraging Information Technology Infrastructure to Facilitate a Firm's Customer Agility and Competitive Activity: An Empirical Investigation. Journal of Management Information Systems, 28 (4), 231-269.

[43] Saisana, M., Saltelli, A. Tarantola, S., (2005). Uncertainty and sensitivity analysis techniques as tools for the quality assessment of composite indicators. Journal of the Royal Statistical Society. Series A (Statistics in Society), 168(2), 307-323.

[44] Schokkaert, E., (2007) Capabilities and satisfaction with life. Journal of Human Development, 8, 415-30.

[45] Scherer, F.M., (1996). An Accidental Schumpeterian. Economist, 5(3).

[46] Schumpeter, J. A., (1942). Capitalism, Socialism and Democracy. New York: Harper and Brothers.

[47] Schumpeter, J. A., (1934). The Theory of Economic Development: an inquiry into profits, capital, credit, interest, and the business cycle.

[48] Sheng, H., Nah, F. F., Siau, K., (2005). Strategic implications of mobile technology: A case study using Value-Focused Thinking. The Journal of Strategic Information Systems, 14(2), 269-290.

[49] Smith, H. S., and Waters, R., (2011). Scientific Labour Markets, Networks and Regional Innovation Systems. Regional Studies, 45(7), 961-976.

[50] Stapleton, L. and Garrod, G., (2007) Keeping things simple: why the Human Development Index should not diverge from its equal weights assumption, Social Indicators Research, 84, 179-88.

[51] Sundbo, J., (1998). The Theory of Innovation: Entrepreneurs, Technology and Strategy. Edward Elgar Publishing.
[52] Timmer, M. P., and van Ark, B., (2005). Does information and communication technology drive EU-US productivity growth differentials? Oxford Economic Papers 57, 693-716

[53] Twining, J., (1999). A naturalistic journey into the collaboratory: In search of understanding for prospective participants. Retrieved August 20, 2006, from ProQuest database.

[54] Varnali, K., Toker, A., (2010). Mobile marketing research: The-state-of-the-art. International Journal of Information Management, 30(2), 144-151.

[55] West, D. M., (2012). How Mobile Technology is Driving Global Entrepreneurship. Technical Report, Brookings Institute.

[56] Wu, J. W., Wanga, S. (2005). What drives mobile commerce? An empirical evaluation of the revised technology acceptance model, Information and Management 42 (2005) 719-729.

[57] Yang, K., (2012). Consumer technology traits in determining mobile shopping adoption: An application of the extended theory of planned behavior. Journal of Retailing and Consumer Services, 19, 484-491.

[58] Zhang, J. F., Wu, Z. J., Feng, P. F., Yu, D. W., (2011). Evaluation systems and methods of enterprise informatization and its application. Expert Systems with Applications, 38, 8938-8948.

[59] Zhu, K., Kraemer, K. L., Xu, S., (2006). The Process of Innovation Assimilation by Firms in Different Countries: A Technology Diffusion Perspective on E-Business. Management Science, 52 (10), 1557-1576.

[60] Bulligan, B., Golinelli, R., and Parigi, G., (2010), Forecasting monthly industrial production in real-time: from single equations to factor-based models, Empirical Economics, 39, (2), 303-336 